American Journal of Pharmacology and Toxicology 1 (3): 60-64, 2006

ISSN 1557-4962

(C) 2006 Science Publications

\title{
Internalizing Versus Non-internalizing Receptors for Targeting L-Methioninase to Cancer Cells
}

\author{
${ }^{1}$ Xiao-Ping Zang, ${ }^{2}$ Naveen R. Palwai, ${ }^{1}$ J. Thomas Pento and ${ }^{2}$ Roger G. Harrison \\ ${ }^{1}$ Department of Pharmaceutical Science, College of Pharmacy, University of Oklahoma \\ Health Sciences Center, 1110 N. Stonewall Ave., Oklahoma City, Oklahoma 73117, U.S.A. \\ ${ }^{2}$ Bioengineering Center and the School Chemical, Biological and Materials Engineering \\ University of Oklahoma, 100 E. Boyd St., Norman, Oklahoma 73019, U.S.A.
}

\begin{abstract}
We reported previously that L-methioninase targeted to the urokinase receptor of MCF-7 breast cancer cells is significantly more effective in inhibiting cell proliferation and migration than free L-methioninase both in vitro and in vivo. L-methioninase was targeted by linking at its amino terminus to an amino-terminal fragment (ATF) of urokinase. The ATF was selected for targeting because is has previously been shown not to internalize within the cells. The present study was designed to determine the effectiveness of targeting L-methioninase to a cancer cell receptor that is internalizing in comparison with ATF-methioninase, which does not internalize. Transforming growth factor- $\alpha$ (TGF$\alpha$ ) was selected for targeting to the epidermal growth factor receptor which is overexpressed in numerous cancer cell lines and is an internalizing receptor. Two fusion proteins, ATF-methioninase and TGF-methioninase (TGF- $\alpha$ linked to the amino terminus of L-methioninase), were produced by recombinant methods and purified. In an in vitro culture wounding assay over 3 days to measure cell proliferation and migration of MCF-7 breast cancer cells and PC-3 prostate cancer cells, both fusion proteins inhibited the proliferation and migration of both cancer cell lines. However, the inhibition was significantly greater for ATF-methioninase compared to TGF-methioninase, especially at treatment days 2 and 3. These results indicate that, for a fixed dosage of the fusion protein, it is more advantageous to have L-methioinase bind to a receptor and remain externalized, rather than to bind to a receptor which leads to internalization of L-methioninase. Further, it may be advantageous to target other anticancer agents to the urokinase receptor on the cancer cell surface by means of the aminoterminal fragment of urokinase.
\end{abstract}

Key words: Breast cancer, prostate cancer, L-methioninase, transforming growth factor- $\alpha$, urokinase amino-terminal fragment

\section{INTRODUCTION}

Methionine-dependence is a metabolic defect of cancer cells that is under investigation for the treatment of cancer. Many cancer cell lines have been found to have this defect ${ }^{[1]}$. A strategy to exploit the methionine dependence of cancer cells is the administration of the enzyme L-methioninase, which degrades methionine (see the review by Cellarier et al.[2]). In one promising study, the i.v. infusion of L-methioninase for 24 hours to nine patients with either advanced lung, breast or kidney cancer, or lymphoma in a phase I clinical trial resulted in serum methionine being reduced to very low levels, with no adverse side effects observed ${ }^{[3]}$.
In a recent study, we showed that L-methioninase targeted to the urokinase receptor of MCF-7 breast cancer cells is significantly more effective in inhibiting cell proliferation and migration than free Lmethioninase $^{[4]}$. A fusion protein consisting of aminoterminal fragment of the A chain of human urokinase (ATF, amino acids 1-49) linked to the amino terminus of L-methioninase from Pseudomonas putida produced a dose-dependent inhibition of both the proliferation and migration of MCF-7 cells in vitro ${ }^{[4,5]}$ and inhibition of MCF-7 tumor xenografts in vivo ${ }^{[4]}$. ATF was selected for this fusion protein because previous studies have shown that residues 12-32 of the urokinase A chain are critical for binding to the receptor ${ }^{[6]}$ and that
Corresponding Author:
Roger G. Harrison, Bioengineering Center and the School Chemical, Biological and Materials Engineering, University of Oklahoma, 100 E. Boyd St., Norman, Oklahoma 73019, U.S.A., Tel: 4053254367, Fax: 4053255813 
the amino-terminal fragment of the A chain, consisting of residues 1-135 does not internalize within the cell, since the catalytic domain in the urokinase $\mathrm{B}$ chain is required for internalization ${ }^{[7]}$.

The present study was designed to determine the effectiveness of targeting L-methioninase to a cancer cell receptor that is internalizing and compare the results to those with ATF-methioninase, which does not internalize. We selected transforming growth factor- $\alpha$ (TGF- $\alpha$ ) for targeting to the epidermal growth factor (EGF) receptor, which has been shown to be expressed in numerous cancer cell lines ${ }^{[8]}$ and to be an internalizing receptor ${ }^{[9]}$. TGF- $\alpha$, a $6 \mathrm{kDa}$ polypeptide, binds to the EGF receptor with about the same affinity as EGF for mammalian cells ${ }^{[10]}$.

\section{MATERIALS AND METHODS}

Synthetic oligonucleotides were produced by the Molecular Biology Resource Facility at the University of Oklahoma Health Sciences Center. Vector pET-30 EK/LIC, HRV 3C protease and NovaBlue and BL21(DE3) Escherichia coli cells were obtained from Novagen (Madison, WI). Plasmid containing the TGF- $\alpha$ gene was kindly provided by Dr. Ira Pastan of the National Cancer Institute (pVC387/TGF).

Construction of recombinant expression plasmids: Expression vector pET-30/Ek/LIC/ATF-Meth coding for the ATF-methioninase fusion protein gene with an N-terminal His-tag sequence and an HRV 3C protease cleavage site immediately before the start of ATF has been described ${ }^{[4]}$. HRV 3C protease cleaves the sequence LEVLFQ $\downarrow$ GP.

Expression vector $\mathrm{pET}-44 / \mathrm{Ek} / \mathrm{LIC} / \mathrm{TGF}-\mathrm{Meth}$ was constructed to give an N-terminal His-tag sequence with a NusA tag, integrated thrombin cleavage site, enterokinase cleavage site and an engineered HRV 3C protease cleavage site next to the start of the gene for the TGF-methioninase fusion protein, which has the following sequence: N-(TGF- $\alpha$ )-Gly-Ser-Gly-Ser-GlySer-(L-methioninase)-C. The peptide between TGF- $\alpha$ and L-methioninase is a flexible linker designed to join the two proteins without disturbing their function and is not susceptible to cleavage by host protease ${ }^{[11]}$. The NusA tag ${ }^{[12]}$ was selected for use to insure that the fusion protein was soluble. This gene construction was performed as follows: The DNA sequence encoding the L-methioninase was amplified by polymerase chain reaction (PCR) from pKK223-3/ATF-Meth ${ }^{[5]}$ with a BamHI site at the $5^{\prime \prime}$ end and a LIC site at the $3^{\prime \prime}$ end and the DNA sequence encoding TGF- $\alpha$ was amplified by PCR from pVC 387/TGF with the LIC site and HRV
3C protease site at the 5' end and the flexible linker and BamHI site at the 3' end. PCR was performed using the Expand High Fidelity PCR system (Boehringer Mannheim, Indianapolis, Ind.). Forward and reverse primers used for PCR for TGF-methioninase were as follows:

a. The primer TGF 5, (GACGACGACAAGATGCTTGAAGTCCTCTTTC AGGG ACCCGGAGTGGTGTCCCATTTTAATGACTG

CCC) introduced at the 5 ' end of the TGF DNA sequence an LIC cloning site (italics) and an HRV 3C protease site (underlined);

b. The primer

TGF

3'(GCGGATCCAGAACCGCTGCCAGCCAGGA GGTCC GCATGCTCACAGCG) introduced at the 3 ' end of the TGF DNA sequence a BamHI site (bold italics) and flexible linker region (underlined);

c. The primer METH 5,

(CGCGGATCCCGCGACTCCCATAACAACAC

C) introduced at the 5' end of the L-methioninase DNA sequence a BamHI site (bold italics).

d. The primer METH 3'(GAGGAGAAGCCCGGTTATCATGCACACG

CCT CCAATGCCAACTCG) introduced at 3' end of the L-methioninase DNA sequence an LIC cloning site (italics).

PCR gene fragments were agarose gel-purified prior to restriction enzyme digestion according to the Qiagen protocol (BIO101, Vista, CA). After digestion of these gene fragments with BamHI enzyme, they were purified using a PCR purification kit (Qiagen, BIO101, Vista, CA). The two fragments were ligated using T4 DNA ligase. Ligated product was purified according to the Qiagen protocol (BIO101, Vista, CA). The ligated product was annealed to the pET-44 EK/LIC linear vector and transformed into NovaBlue $E$. coli cells. The DNA sequences were verified by sequencing at the Oklahoma Medical Research Foundation (Oklahoma City, OK).

Expression and purification of recombinant proteins: Fusion proteins containing the ATFmethioninase or TGF-methioninase were produced in E. coli BL21(DE3) containing pET-30/Ek/LIC/ATFMeth or pET-44/Ek/LIC/TGF-Meth vectors and purified as described ${ }^{[4]}$, with the following exceptions: Cells containing pET-44/Ek/LIC/TGF-Meth were grown in medium with $100 \mu \mathrm{g} \mathrm{mL}^{-1}$ ampicillin (instead of $35 \mu \mathrm{g} \mathrm{mL} \mathrm{m}^{-1}$ kanamycin) and recombinant protein expression was induced for a period of $3 \mathrm{~h}$ at $37^{\circ} \mathrm{C}$ (instead of $5 \mathrm{~h}$ at $30^{\circ} \mathrm{C}$ ). 
Cell culture: MCF-7 and PC-3 human cancer cells were obtained from American Type Culture Collection and maintained as monolayer cultures in RPMI 1640 media (without phenol red) supplemented with $2 \mathrm{mM}$ L-glutamine, gentamicin $\left(50 \mu \mathrm{g} \mathrm{mL}^{-1}\right)$, penicillin $(100$ units $\left.\mathrm{mL}^{-1}\right)$, streptomycin $\left(100 \mu \mathrm{g} \mathrm{mL}^{-1}\right)$, estradiol $\left(10^{-}\right.$ ${ }^{11}$ M) (all from Sigma, St. Louis, MO) and 5\% bovine calf serum (Hyclone, Logan, UT) as previously described $^{[13]}$. The media was filter sterilized and stored at $4^{\circ} \mathrm{C}$ prior to use.

Culture wounding assay: Cell migration and proliferation were evaluated using the culture wounding assay as previously described ${ }^{[5,13]}$. Three days after seeding $5 \times 10^{5}$ the cancer cells into $60 \mathrm{~mm}$ culture dishes when the cells were approximately $90 \%$ confluent, the cultures were wounded, washed three times with PBS and treated with media containing fusion protein. In each experiment control cultures received RPMI media alone. At 24, 48 and $72 \mathrm{~h}$ following treatment, cell migration and proliferation were determined by measuring both the distance traveled by the cell front into the wounded area (migration) and the number of cells in the wounded area (proliferation)/microscopic field. Measurements were taken from 10-12 individual microscopic fields in each experiment and data was summarized from 2-3 experiments.

Data analysis: Multiple group comparisons were conducted using ANOVA and Student's t-test for pairwise comparisons. Group differences resulting in $p$ values of less than 0.05 were considered to be statistically significant.

\section{RESULTS AND DISCUSSION}

Expression and purification of fusion proteins: Both fusion proteins were produced in soluble form at either $30^{\circ} \mathrm{C}$ (ATF-methioninase) or $37{ }^{\circ} \mathrm{C}$ (TGFmethioninase) in E. coli BL21(DE3) cells after transformation with the recombinant plasmid. The SDS-PAGE results in Fig. 1 show the expression of the TGF-methioninase fusion protein in a clone containing the recombinant plasmid. Very near complete cleavage at the HRV $3 \mathrm{C}$ protease site to remove the His-tag was obtained using $\mathrm{HRV} 3 \mathrm{C}$ protease (Fig. 1, lanes 2 and 3). The purity of the fusion protein from the final chromatography was estimated to be $97 \%$ using Quantity One densitometry software analysis of lane 4 of the SDS-PAGE gel in Fig. 1 (BioRad, Hercules, CA, USA). Similar expression and purity were also obtained with ATF-methioninase ${ }^{[4]}$.

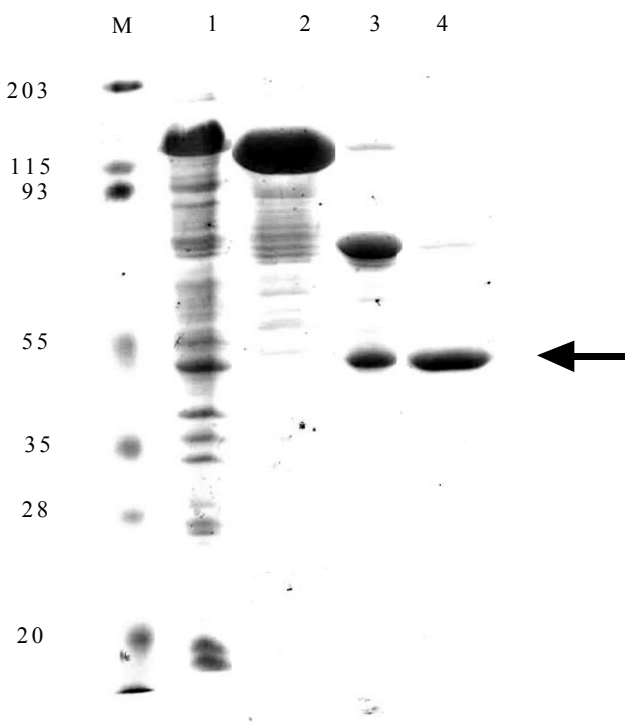

Fig. 1: SDS-PAGE analysis with Coomassie blue staining of the expression and purification of the TGFmethioninase fusion protein (position indicated by the arrow). The fusion protein was expressed from plasmid $\mathrm{pET}-44 / \mathrm{Ek} / \mathrm{LIC} / \mathrm{TGF}-M e t h$ in $E$. coli BL21(DE3) cells at $37{ }^{\circ} \mathrm{C}$ (lane 1 soluble lysate, lane 2 eluted fraction from first metal affinity chromatography, lane 3 eluted fraction after cleavage with HRV 3C protease, lane 4 pooled fractions from second metal affinity chromatography, $M$ marker proteins with molecular masses indicated on the left in kiloDaltons)

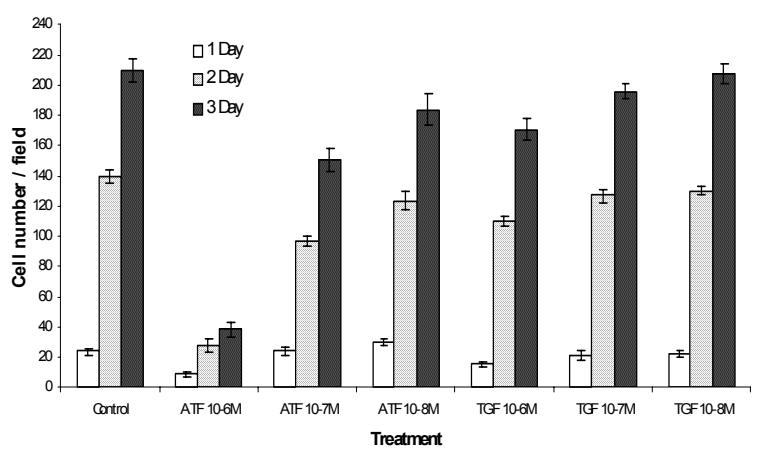

Fig. 2: Dose-response effect of fusion proteins on MCF-7 breast cancer cell proliferation. ATF-methioninase or TGF-methioninase was administered immediately following culture wounding. Each bar represents the number of cells that migrated into the wounded area (mean \pm SEM from 10 to 12 microscope fields)

The specific L-methioninase activity was $12.5 \mathrm{U} \mathrm{mg}^{-1}$ protein for TGF-methioninase and $13.9 \mathrm{U} \mathrm{mg}^{-1}$ protein for ATF-methioninase. Amino acid sequencing of both fusion proteins was performed at the amino-terminus. The predominant sequence was identical to the amino- 


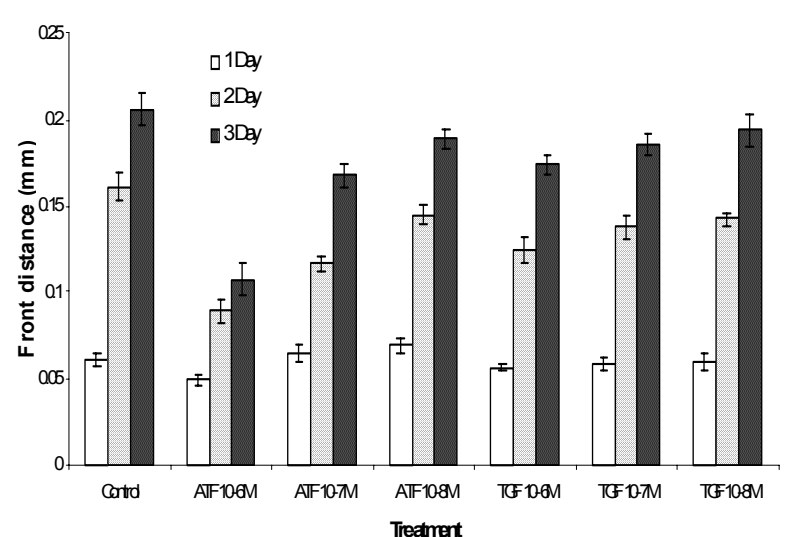

Fig. 3: Dose-response effect of fusion protein on MCF-7 breast cancer cell migration. ATF-methioninase or TGF-methioninase was administered immediately following culture wounding. Each bar represents the distance of cell migration into the wounded area (mean \pm SEM from 10 to 12 microscope fields)

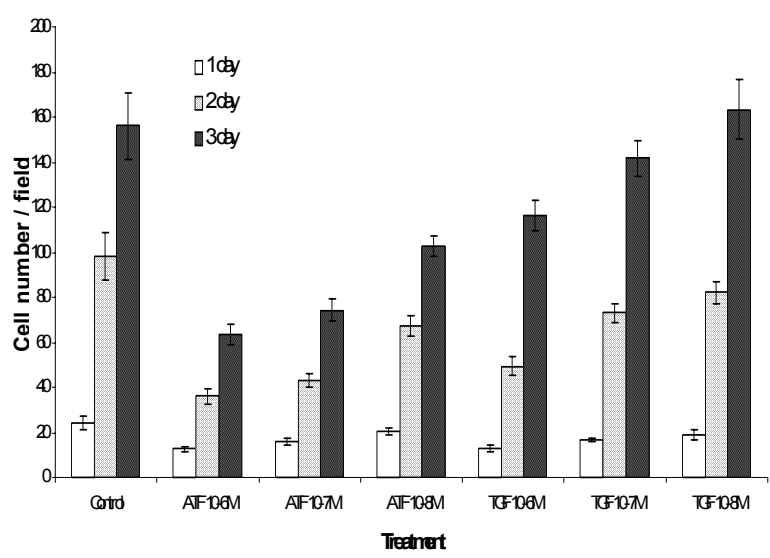

Fig. 4: Dose-response effect of fusion protein on PC-3 prostate cancer cell proliferation. ATF-methioninase or TGF-methioninase was administered immediately following culture wounding. Each bar represents the number of cells that migrated into the wounded area (mean \pm SEM from 10 to 12 microscope fields)

terminus of TGF- $\alpha$ or urokinase A chain with Gly-Pro added for the first 7-8 amino acids.

Inhibitory effects of fusion proteins on MCF-7 breast cancer cells: The effects of the fusion proteins on MCF-7 breast cancer cells were examined over a concentration range of $10^{-6}$ to $10^{-8} \mathrm{M}$ as shown in Fig. 2 and 3 . In these experiments, TGF-methioninase produced a dose-related inhibition of cell proliferation and migration compared to the control. However, treatment with ATF-methioninase in general produced a much greater inhibition of cell proliferation and migration than that observed with TGF-methioninase

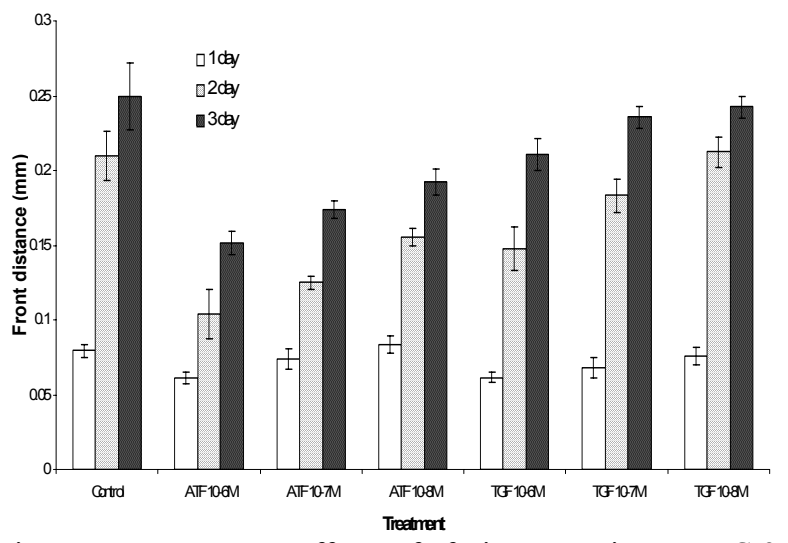

Fig. 5: Dose-response effect of fusion protein on PC-3 prostate cancer cell migration. ATF-methioninase or TGF-methioninase was administered immediately following culture wounding. Each bar represents the distance of cell migration into the wounded area (mean \pm SEM from 10 to 12 microscope fields)

treatment. ATF-methioninase-induced inhibition of the MCF-7 cells was significantly greater than that induced by TGF-methioninase on treatment days 2 and 3 at both at the highest two concentrations of $10^{-6} \mathrm{M}$ and $10^{-7} \mathrm{M}$ $(\mathrm{p}<0.05)$.

Inhibitory effects of fusion proteins $\mathrm{PC}-3$ prostate cancer cells: The effects of the fusion proteins on PC-3 prostate cancer cells were examined over a concentration range of $10^{-6}$ to $10^{-8} \mathrm{M}$ as shown in Fig. 4 and 5. TGF-methioninase treatment again led to a doserelated inhibition of cell proliferation and migration compared to the control. However, treatment with ATFmethioninase in general produced a much greater inhibition of cell proliferation and migration than TGFmethioninase. ATF-methioninase-induced inhibition of the PC-3 cells was significantly greater than that induced by TGF-methioninase on treatment days 2 and 3 at all the concentrations tested $(\mathrm{p}<0.05)$.

We have previously reported that the ATFmethioninase fusion protein is significantly more effective than free L-methioninase in inhibiting proliferation and migration of MCF-7 breast cancer cells both in cell culture and in nude mouse xenografts in vivo ${ }^{[4,5]}$. The objective of this study was to determine if L-methioninase is as effective as an anticancer agent when it is targeted to an internalizing receptor compared to when it is targeted to a non-internalizing receptor. The MCF-7 breast cancer cells and PC-3 prostate cancer cells chosen for targeting in this study previously have been shown to be methionine dependent $^{[14]}$ and to express both the urokinase and EGF receptors ${ }^{[15-18]}$.

While both fusion proteins produced inhibition of cell proliferation and migration of both the MCF-7 and 
PC-3 cancer cells, the inhibition was significantly greater for ATF-methioninase compared to TGFmethioninase, especially for days 2 and 3 after treatment. These results indicate that, for a fixed dosage of the fusion protein, it is more advantageous to have Lmethioinase to bind to the receptor and stay bound on the cell surface, rather that to have L-methioninase to bind to the receptor and then to be brought into the inside of the cell by the internalizing receptor. In conclusion, it may be advantageous to target other anticancer agents to the urokinase receptor on the cancer cell surface by means of the amino-terminal fragment of urokinase.

\section{ACKNOWLEDGEMENTS}

This study was supported in part by grants from the Oklahoma Center for the Advancement of Science and Technology and from the Presbyterian Health Foundation.

\section{REFERENCES}

1. Hoffman, R., 1982. Methionine dependence in cancer cells - A review. In Vitro, 18: 421-428.

2. Cellarier, E., X. Durando, M. Vasson, M. Farges, A. Demiden, J. Maurizis, J. Madelmont and P. Chollet, 2003. Methionine dependency and cancer treatment. Cancer Treat. Rev., 29: 489-499.

3. Tan, Y., J. Zavala, Sr., Q. Han, M. Xu, X. Sun, X. Tan, R. Magana, J. Geller and R. Hoffman, 1997. Recombinant methioninase infusion reduces the biochemical endpoint of serum methionine with minimal toxicity in high-stage cancer patients. Anticancer Res., 17: 3857-3860.

4. Zang, X., N. Palwai, M. Lerner, D. Brackett, J. Pento and R. Harrison, 2006. Targeting a methioninase-containing fusion protein to breast cancer urokinase receptors inhibits growth and migration. Anticancer Res., 26: 1745-1751.

5. Peron, K., T. Jones, S. Gauthier, T. Nguyen, X. Zang, M. Barriere, D. Preveraud, C. Soliman, R. Harrison and J. Pento, 2003. Targeting of a novel fusion protein containing methioninase to the urokinase receptor to inhibit breast cancer cell migration and proliferation. Cancer Chemother. Pharmacol., 52: 270-276.

6. Appella, E., E. Robinson, S. Ullrich, M. Stoppelli, A. Corti, G. Cassani and F. Blasi, 1987. The receptor-binding sequence of urokinase. A biological function for the growth-factor module of proteases. J. Biol. Chem., 262: 4437-4440.

7. Cubellis, M., T. Wun and F. Blasi, 1990. Receptormediated internalization and degradation of urokinase is caused by its specific inhibitor PAI-1. Embo J., 9: 1079-1085.
8. Heimbrook, D., S. Stirdivant, J. Ahern, N. Balishin, D. Patrick, G. Edwards, D. Defeo-Jones, D. FitzGerald, I. Pastan and A. Oliff, 1990. Transforming growth factor alpha-Pseudomonas exotoxin fusion protein prolongs survival of nude mice bearing tumor xenografts. Proc. Natl. Acad. Sci. USA, 87: 4697-4701.

9. Korc, M., C. Haussler and N. Trookman, 1987. Divergent effects of epidermal growth factor and transforming growth factors on a human endometrial carcinoma cell line. Cancer Res., 47: 4909-4914.

10. Marquardt, H., M. Hunkapiller, L. Hood and G. Todaro, 1984. Rat transforming growth factor type 1: structure and relation to epidermal growth factor. Science, 223: 1079-1082.

11. Argos, P., 1990. An investigation of oligopeptides linking domains in protein tertiary structures and possible candidates for general gene fusion. J. Mol. Biol., 211: 943-958.

12. Davis, G., C. Elisee, D. Newham and R. Harrison, 1999. New fusion protein systems designed to give soluble expression in Escherichia coli. Biotechnol. Bioeng., 65: 382-388.

13. Zang, X., M. Lerner, S. Dunn, D. Brackett and J. Pento, 2003. Antisense KGFR oligonucleotide inhibition of KGF-induced motility in breast cancer cells. Anticancer Res., 23: 4913-4919.

14. Mecham, J., D. Rowitch, C. Wallace, P. Stern and R. Hoffman, 1983. The metabolic defect of methionine dependence occurs frequently in human tumor cell lines. Biochem. Biophys. Res. Commun., 117: 429-434.

15. Li, Y., N. Wood, D. Yellowlees and P. Donnelly, 1999. Cell surface expression of urokinase receptor in normal mammary epithelial cells and breast cancer cell lines. Anticancer Res., 19: 1223-1228.

16. Arteaga, C., S. Hurd, T. Dugger, A. Winnier and J. Robertson, 1994. Epidermal growth factor receptors in human breast carcinoma cells: a potential selective target for transforming growth factor $\alpha$-Pseudomonas exotoxin 40 fusion protein. Cancer Res., 54: 4703-4709.

17. Hollas, W., N. Hoosein, L. Chung, A. Mazar, J. Henkin, K. Kariko, E. Barnathan and D. Boyd, 1992. Expression of urokinase and its receptor in invasive and non-invasive prostate cancer cell lines. Thromb. Haemost., 68: 662-666.

18. Ching, K., E. Ramsey, N. Pettigrew, R. D'Cunha, M. Jason and J. Dodd, 1993. Expression of mRNA for epidermal growth factor, transforming growth factor-alpha and their receptor in human prostate tissue and cell lines. Mol. Cell. Biochem., 126: 151-158. 